\title{
Isolation of a novel mutant gene for soil-surface rooting in rice (Oryza sativa L.)
}

\author{
Eiko Hanzawa' ${ }^{1}$, Kazuhiro Sasaki ${ }^{1,2,3}$, Shinsei Nagai ${ }^{1}$, Mitsuhiro Obara ${ }^{3}$, Yoshimichi Fukuta ${ }^{3}$, Yusaku Uga ${ }^{4}$, \\ Akio Miyao ${ }^{4}$, Hirohiko Hirochika ${ }^{4}$, Atsushi Higashitani ${ }^{1}$, Masahiko Maekawa ${ }^{5}$ and Tadashi Sato ${ }^{1,6^{*}}$
}

\begin{abstract}
Background: Root system architecture is an important trait affecting the uptake of nutrients and water by crops. Shallower root systems preferentially take up nutrients from the topsoil and help avoid unfavorable environments in deeper soil layers. We have found a soil-surface rooting mutant from an $\mathrm{M}_{2}$ population that was regenerated from seed calli of a japonica rice cultivar, Nipponbare. In this study, we examined the genetic and physiological characteristics of this mutant.
\end{abstract}

Results: The primary roots of the mutant showed no gravitropic response from the seedling stage on, whereas the gravitropic response of the shoots was normal. Segregation analyses by using an $F_{2}$ population derived from a cross between the soil-surface rooting mutant and wild-type Nipponbare indicated that the trait was controlled by a single recessive gene, designated as sor1. Fine mapping by using an $F_{2}$ population derived from a cross between the mutant and an indica rice cultivar, Kasalath, revealed that sor1 was located within a 136-kb region between the simple sequence repeat markers RM16254 and 2935-6 on the terminal region of the short arm of chromosome 4, where 13 putative open reading frames (ORFs) were found. We sequenced these ORFs and detected a 33-bp deletion in one of them, Os04g0101800. Transgenic plants of the mutant transformed with the genomic fragment carrying the Os04g0101800 sequence from Nipponbare showed normal gravitropic responses and no soil-surface rooting.

Conclusion: These results suggest that sor1, a rice mutant causing soil-surface rooting and altered root gravitropic response, is allelic to Os04g0101800, and that a 33-bp deletion in the coding region of this gene causes the mutant phenotypes.

Keywords: Root system architecture; Gene isolation; Soil-surface rooting; Shallow rooting; Gravitropic response

\section{Background}

Root system architecture is an important trait for plant growth and crop yield because it affects the uptake of nutrients and water, which are unevenly distributed in the soil. Diversity of the vertical distribution of the root systems of different species allows efficient maximization of plant growth and crop yields in unfavorable environments with poor resource mobility, such as infertile or arid fields (Hodge et al. 2009; Rich and Watt 2013). Shallow root systems enhance phosphorus acquisition in

\footnotetext{
*Correspondence: tadashi@ige.tohoku.ac.jp

'Graduate School of Life Sciences, Tohoku University, 2-1-1 Katahira, Aoba-ku,

Sendai, Miyagi 980-8577, Japan

${ }^{6}$ RIKEN Innovation Center, Ion Beam Breeding Laboratory, 2-1 Hirosawa,

Wako, Saitama 351-0198, Japan

Full list of author information is available at the end of the article
}

common bean (Ge et al. 2000; Liao et al. 2004; Lynch 2011) and wheat (Manske et al. 2000). Phosphorus-efficient bean cultivars have shallower basal roots and more adventitious rooting in the topsoil than other bean cultivars (Lynch and Brown 2001). In teosintes, adventitious root formation at the soil surface may provide an alternative growth strategy to cope with soil flooding or waterlogging (Mano et al. 2005). Therefore, shallower root systems preferentially take up nutrients from the topsoil and help to avoid unfavorable environments in deeper soil layers.

When submerged, Indonesian rice (Oryza sativa L.) cultivars that belong to the Bulu ecotype develop thick primary roots above and near the soil surface (Lafitte et al. 2001; Ueno and Sato 1989, 1992). These authors suggested that soil-surface and shallow roots contribute to the avoidance of hypoxic soils in rice. Rice superficial

\section{实}


roots develop near the soil surface from the beginning of the spikelet differentiation stage to the fully ripe stage (Morita and Yamazaki 1993). The fresh weight of superficial roots is positively correlated with yields in paddy fields (Morita and Yamazaki 1993). Thus, soil-surface and shallow roots may contribute to the avoidance of hypoxic environments and promote rice growth.

Genetic analyses of root system architecture have been performed in a variety of rice lines; however, no genes controlling soil-surface rooting have been isolated by using natural variation. A study of 81 diverse genotypes in rice revealed two DNA molecular markers associated with shallow and deep rooting on chromosomes 9 and 10, respectively (Chaitra et al. 2006). Uga et al. (2012) identified four quantitative trait loci (QTLs) for soil-surface rooting on chromosomes $3,4,6$, and 7 by using recombinant inbred lines derived from a cross between an Indonesian rice cultivar with soil-surface roots and a Japanese cultivar without such roots. The use of mutants is an alternative approach to isolate causal genes for traits of interest. Rice mutants have been isolated for the following root morphological characteristics: inhibition of root growth, absence of crown roots, short lateral roots or absence of lateral roots, short root hairs, and hairless roots (Chhun et al. 2003; Debi et al. 2003, 2005; Hao and Ichii 1999; Ichii and Ishikawa 1997; Inukai et al. 2001; Iwao et al. 2005; Kim et al. 2007; Suzuki et al. 2003; Yuo et al. 2009, 2011). Although many rice mutants for the above traits have been reported, no causal genes for soil-surface rooting have been cloned. Here, we describe a rice mutant with thick primary roots that develop above and immediately under the soil surface. The purpose of this study was to isolate and characterize the mutant gene responsible for soil-surface rooting.

\section{Results}

\section{Evaluation of the mutant phenotype}

To evaluate the soil-surface rooting phenotype of the mutant, we used four different methods: the pot method, the cup method, the glass tube method, and the basket method. Under submerged conditions, the roots of all mutant plants elongated on or just below the soil surface in plant pots (Figure 1A); however, no wild-type Nipponbare plants (WT) had such roots during the seedling stage (Figure 1B). The cup method showed that mutant plants had many soil-surface roots (Figure 1C); however, WT had very few such roots (Figure 1D). The glass tube method showed that mutant plants had many primary roots elongated on the upper side of the agar surface (Figure 1E); however, WT had no such roots (Figure 1F). The basket method showed that mutant plants had many soil-surface roots (Figure 1G); however, WT had few soilsurface roots (Figure $1 \mathrm{H}$ ). These results revealed that our mutant is a novel mutant for soil-surface rooting.
Distribution of primary roots assessed by basket method The primary roots of the mutant plants tended to be distributed horizontally at the third (Figure 2A and D), fifth (Figure $2 \mathrm{~B}$ and $\mathrm{E}$ ), and seventh leaf stages (Figure $2 \mathrm{C}$ and F). More than $88 \%$ of the primary roots in the mutant (Figure $2 \mathrm{~A}-\mathrm{C}$ ), but less than $45 \%$ in the WT (Figure 2D-F) had a vertical growth angle of $<30^{\circ}$ (soil surface $=$ vertical angle of $0^{\circ}$ ) at any of the examined leaf stages. These results suggest that the primary roots of the mutants elongated on or near the soil surface from early seedling stages on, whereas those of WT tended to elongate toward the direction of gravity.

\section{Gravitropic responses of roots and shoots}

The gravitropic responses of seminal roots in WT and mutant seeds were evaluated in an agar tray assay (Figure 3AC). Prior to rotation, the mutant roots were growing in random directions, whereas WT roots elongated along the direction of gravity (Figure 3D). After the trays were rotated $90^{\circ}$, the mutant roots continued to extend randomly, whereas those of WT bent in the direction of gravity within $10 \mathrm{~h}$ (Figure 3E). Although the direction of the seminal roots of the mutants was irregular before and after rotation, their shoots grew normally against the direction of gravity (Figure 3F). Furthermore, the mutant crown roots extended randomly, whereas the WT crown roots grew in the direction of gravity. These results suggest that the primary roots of the mutant lack a gravitropic response from the seedling stage on, whereas the shoots show normal gravitropic response.

\section{Relationship between soil-surface rooting and gravitropic response}

To determine whether the soil-surface rooting and the lack of root gravitropic response observed in the mutant are controlled by the same gene, we performed segregation analyses by using $85 \mathrm{~F}_{2}$ plants derived from a cross between the mutant and WT Nipponbare (Table 1). The gravitropic responses of seminal roots of each $\mathrm{F}_{2}$ plant were evaluated in the agar tray assay (Figure $3 \mathrm{~A}-\mathrm{C}$ ). The primary roots of $60 \mathrm{~F}_{2}$ plants responded to gravity similarly to WT Nipponbare roots. In contrast, the primary roots of the remaining 25 plants showed gravity-insensitivity that was similar to that of the mutant. The ratio of gravitysensitive plants to insensitive plants was not significantly different from 3:1 ( $\left.X^{2}=0.797, P=0.372\right)$.

In the $60 \mathrm{~F}_{2}$ plants that had gravity-sensitive roots, the soil-surface rooting ratio was $11.4 \%$ or less (Table 1 ). In contrast, the remaining 25 plants had a soil-surface rooting ratio of $52.6 \%$ or more. These results suggest that soilsurface rooting at the seedling stage is controlled by a single recessive gene that also controls the lack of response to gravity beginning at germination. We designated the 

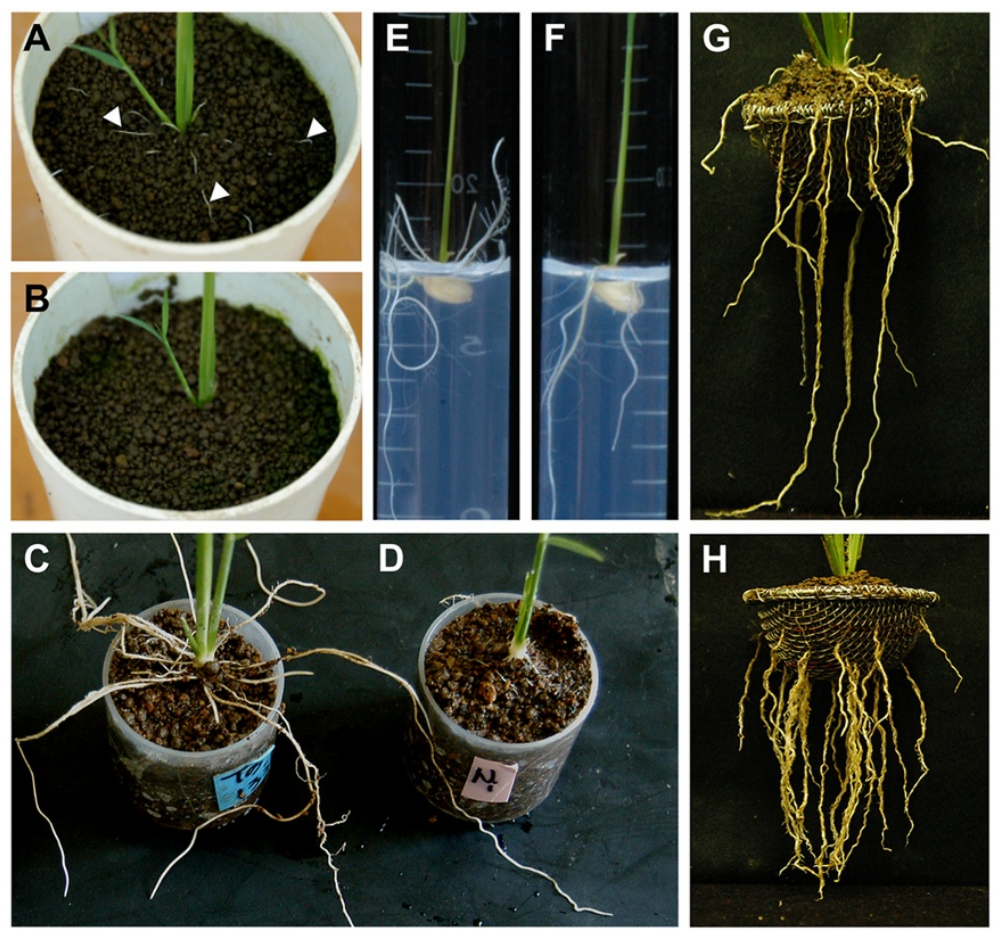

Figure 1 Differences in rooting between the sor1 mutant ( $A, C, E$, and $G)$ and wild-type Nipponbare (B, D, F, and H). Plants were grown in pots under waterlogged conditions ( $\mathbf{A}$ and $\mathbf{B})$, by the cup method (C and $\mathbf{D})$, by the glass tube method ( $\mathbf{E}$ and $\mathbf{F}$ ), or by the basket method ( $G$ and $\mathbf{H}$ ). White arrowheads in (A) indicate soil-surface roots.

recessive mutant gene as sor1 (soil-surface rooting 1) and the corresponding locus as SOR1.

\section{Mapping of the mutant sor1 gene}

We used the cup method to determine the soil-surface rooting ratio of $\mathrm{F}_{2}$ plants derived from a cross between the mutant and Kasalath, which has a soil-surface rooting ratio similar to that of Nipponbare (data not shown). Among $103 \mathrm{~F}_{2}$ plants, 19 had soil-surface rooting ratios similar to those of the mutant, and the remaining 84 plants were normal. The ratio of Nipponbare-type (normal) to SOR-type (soil-surface rooting) plants was not significantly different from $3: 1\left(\chi^{2}=2.359, P=0.125\right)$. Rough mapping was carried out by using the 19 SOR-type plants and 70 DNA markers known to be polymorphic between Nipponbare and Kasalath (Additional file 1). RM551 in the terminal region of the short arm of chromosome 4 (Figure 4A) was the only marker for which the Nipponbare allele was detected in all SOR-type plants. This result indicated that the Nipponbare allele of RM551 co-segregated with the sor 1 mutant allele.

To narrow the candidate region for sor1, $647 \mathrm{~F}_{2}$ plants were used for fine mapping. The phenotype of each $\mathrm{F}_{2}$ plant was evaluated individually by the glass tube method (which is less labor-intensive than the cup method). As in previous experiments (Figure 1E), the mutant roots elongated on the agar surface and extended against the direction of gravity, whereas the roots of Kasalath elongated into the agar along the direction of gravity (data not shown). A total of 498 and 149 plants were of the Nipponbare-type and SOR-type, respectively, and the segregation ratio was not significantly different from 3:1 $\left(\chi^{2}=1.340, P=0.247\right)$. Fine-mapping analyses with seven markers on chromosome 4 (RM16254, 442-9, RM551, 442-5, 2935-6, R2373, and RM335; Additional file 2) were performed to identify the markers flanking the sor 1 gene. Six recombination events were detected between RM16254 and 442-9, and one recombination event was detected between $442-5$ and 2935-6 (Figure 4A). The Nipponbare alleles of markers 442-9, RM551, and 442-5 co-segregated with the sor 1 mutant. These results indicated that sor 1 is located between markers RM16254 and 2935-6. The interval defined by RM16254 and 2935-6 spans approximately $136 \mathrm{~kb}$, according to theNipponbare genome sequence (IRGSP build 5; International Rice Genome Sequencing Project 2008 (http://rgp. dna.affrc.go.jp/E/IRGSP/Build5/build5.html).

\section{Sequence analysis of SOR1}

According to the Rice Annotation Project Database (http:// rapdb.dna.affrc.go.jp/), a total of 13 putative ORFs are located in the 136-kb sor 1 candidate genomic region. To determine whether any of these genes are mutated relative to wild-type Nipponbare, we sequenced the genomic DNAs of all 13 candidate genes from Nipponbare and the mutant. A 

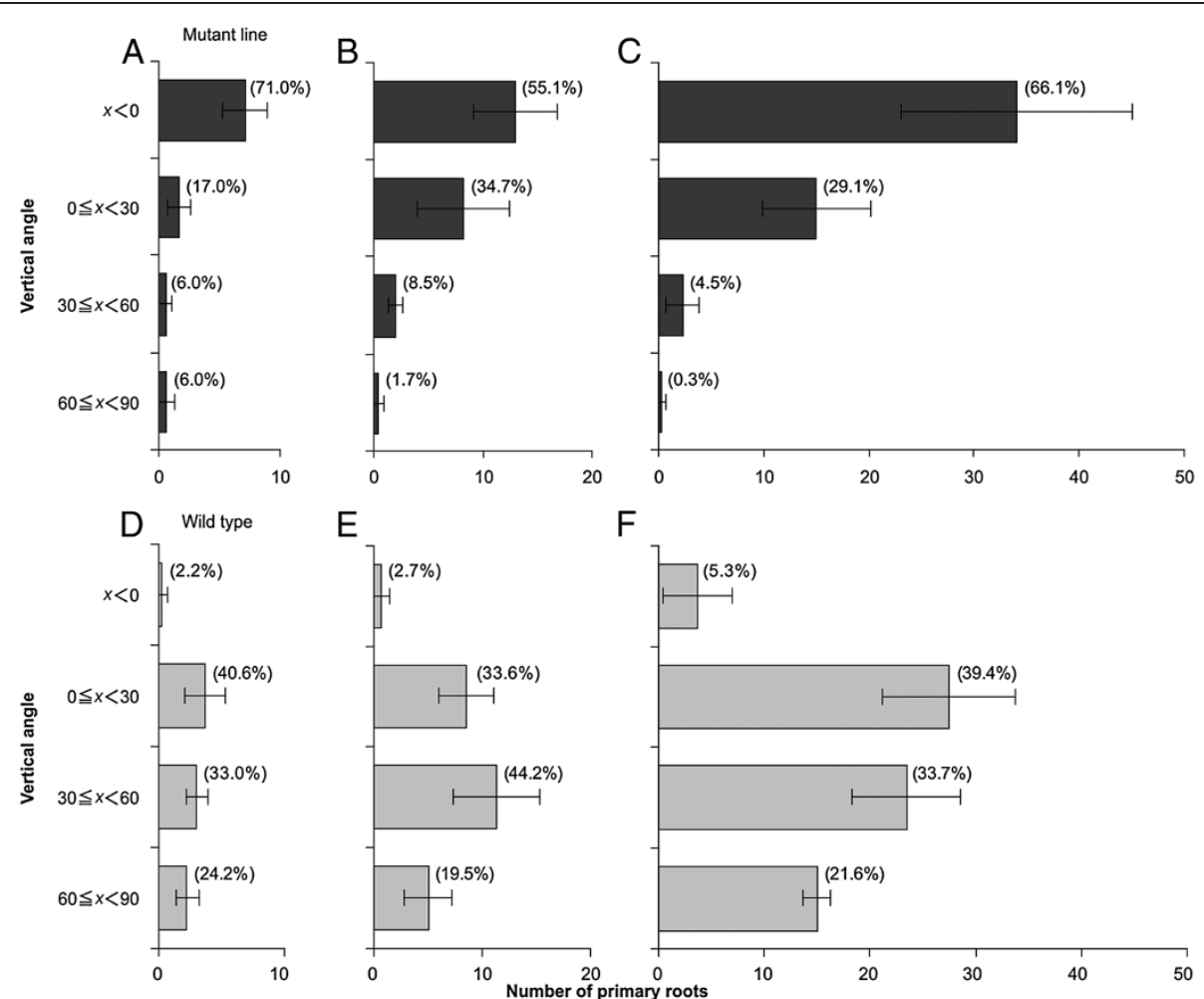

$\mathrm{F}$

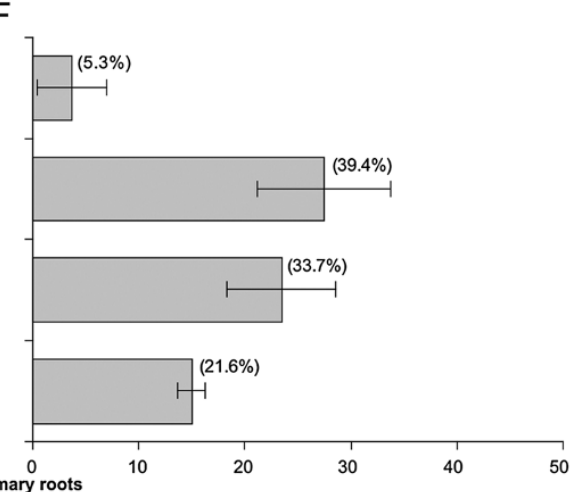

Figure 2 Distribution of primary roots between vertical-angle zones in the sor1 mutant (A, B, and C) and wild-type Nipponbare (D, E, and F), grown under waterlogged conditions by using the basket method. The percentages of primary roots in each angle category were assessed at the third ( $\mathbf{A}$ and $\mathbf{D})$, fifth ( $\mathbf{B}$ and $\mathbf{E})$, and seventh $(\mathbf{C}$ and $\mathbf{F}$ ) leaf stages $(n=9)$, and are shown in parentheses. Error bars indicate SE.

33-bp deletion was detected in the Os04g0101800 ORF, whereas no polymorphisms were detected in the other 12 genes. The protein encoded by Os04g0101800, which we named SOR1, has two domains: a zinc finger (RING) domain (aa124-170) and a von Willebrand factor type A (vWFA) domain (aa279-460) (Figure 4B). The deletion in sor 1 resulted in a loss of 11 amino acids (aa332-342) in the vWFA domain (Figure 4B). On the basis of these data, we concluded that Os04g0101800 was the most likely candidate for the gene mutated in sorl.

\section{Complementation of the candidate gene for sor 1}

To verify that the deletion in Os04g0101800 was responsible for the sor 1 mutant phenotype, we carried out a complementation test. We generated transgenic lines by transformation of the mutant with a 6677-bp genomic DNA fragment from WT Nipponbare containing the entire Os04g0101800 coding region. The presence of the Os04g0101800 transgene was confirmed in two independent transgenic lines, Tg1 and Tg2, by detecting PCR fragments of the same length as in WT (Figure 4C). These lines showed normal seminal root direction when assessed by the glass tube method, and their soil-surface rooting (assessed by the basket method) was similar to that of Nipponbare (Figure 4D). In contrast, transgenic lines created by using an empty vector showed the sor 1 phenotype for both seminal root direction and soil-surface rooting ( $\mathrm{Tg} 3$ in Figure 4C and D). Thus, the complementation analysis demonstrated that the 33-bp deletion in Os04g01 01800 is responsible for the mutant phenotypes.

\section{Phylogenetic analysis of SOR1}

We constructed a phylogenetic tree of rice and Arabidopsis proteins homologous to SOR1 (Figure 5). Phylogenetic analysis showed that rice SOR1 and Arabidopsis WAV3, EDA40, WAVH1, and WAVH2 form a single monophyletic group (Group I), whereas other proteins form a separate cluster (Group II; Figure 5).

\section{Discussion}

The sor1 mutant loses the root-specific gravitropic response at an early growth stage. Consequently, the mutant shows soil-surface rooting under a variety of experimental conditions. A 33-bp deletion in the sor 1 mutant gene compromises the gravitropic response; the results of our complementation analysis indicate that the gravitropic response can be restored by a functional SOR1 gene. The protein encoded by this gene contains the RING and vWFA domains (Figure 4B). Proteins containing the RING domain are involved in auxin signaling (Xie et al. 2002), 


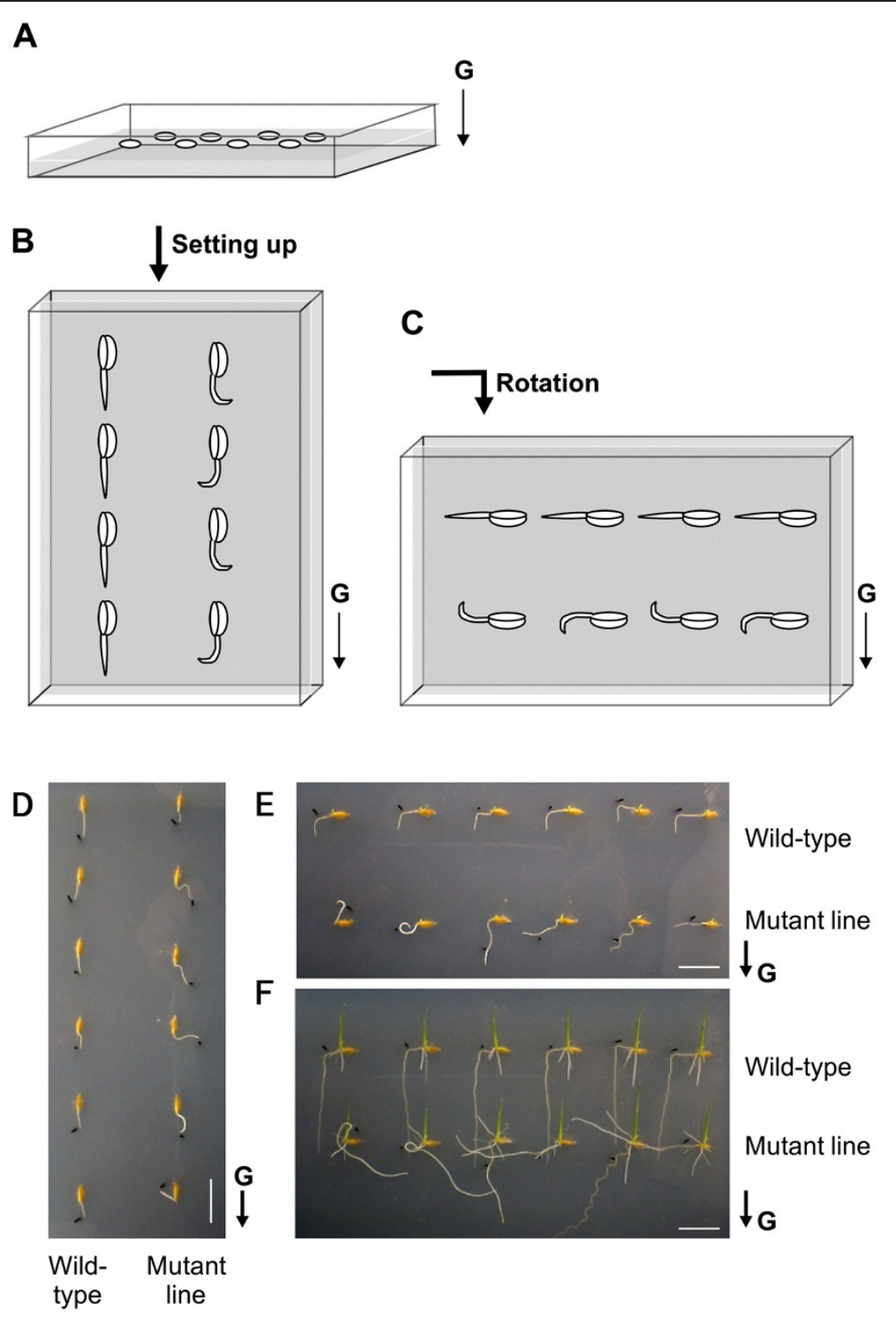

Figure $\mathbf{3}$ Gravitropic response assay for shoots and primary roots at the seedling stage. A diagram illustrating the assay is shown in A-C. Germinated seeds are sown just under the surface of 1.5\% agar in plastic trays with the embryo placed upward (A). Trays were set on their short sides $18 \mathrm{~h}$ after sowing (B) and rotated $90^{\circ}$ clockwise $10 \mathrm{~h}$ later (C). Differences in root gravitropic responses in mutant and Nipponbare seedlings $10 \mathrm{~h}$ after setting the tray on a short edge (D), $10 \mathrm{~h}$ after rotation (E), and $76 \mathrm{~h}$ after rotation (F). Black dots in $\mathbf{D}-\mathbf{F}$ mark the location of seminal root tips just before the rotation. Scale bars, $2 \mathrm{~cm}$. The direction of gravity (G) is indicated by arrows.

photomorphogenesis (Hardtke et al. 2002; Holm et al. 2002), plant defense (Serrano and Guzman 2004), brassinosteroid and pathogen responses (Molnä et al. 2002), light signaling ( $\mathrm{Hu}$ et al. 2002), secretory pathways (Matsuda et al. 2001), seed development (Xu and $\mathrm{Li}$ 2003), and cellular regulation (Stone et al. 2005). Proteins containing the vWFA domain are involved in transcription, DNA repair, ribosomal and membrane transport, and proteasome regulation (Whittaker and Hynes 2002). The vW FA and RING domains are conserved in yeast, plants, and animals. However, proteins that contain both RING and
vWFA domains have been found only in plants, and their physiological functions are unclear. Recently, wavy growth 3 (WAV3), which encodes a protein containing both RING and vWFA domains, was isolated as the causal gene for the wav3 mutant of Arabidopsis (Sakai et al. 2012). The roots of the wav3 mutant show a short-pitch pattern on inclined agar media and a positive gravitropic response. A total of eight genes encoding proteins with both RING and vWFA domains found in the Arabidopsis genome were classified into two subfamilies. Four of these genes, EMBRYO SAC DEVELOPMENT ARREST 40 (EDA40), WAV3, WAV3 


\begin{tabular}{|c|c|c|c|c|}
\hline \multirow[t]{2}{*}{ Plants } & \multirow{2}{*}{$\begin{array}{l}\text { Number } \\
\text { of plants }\end{array}$} & \multicolumn{3}{|c|}{ Soil-surface root ratio $(\%)^{*}$} \\
\hline & & Mean \pm S.D. & Minimum & Maximum \\
\hline Mutant line & 9 & $64.4 \pm 17.3$ & 26.5 & 82.7 \\
\hline $\begin{array}{l}\text { Gravity-insensitive } \\
F_{2} \text { plants }\end{array}$ & 25 & $69.1 \pm 10.1$ & 52.6 & 85.0 \\
\hline $\begin{array}{c}\text { Gravity-sensitive } \\
\mathrm{F}_{2} \text { plants }\end{array}$ & 60 & $2.8 \pm 3.0$ & 0.0 & 11.4 \\
\hline Nipponbare & 9 & $5.1 \pm 4.4$ & 0.0 & 14.1 \\
\hline
\end{tabular}

*The soil-surface rooting ratio was calculated as (the number of primary roots emerged at $x<0^{\circ} /$ the total number of primary roots) $\times 100$.

HOMOLOG 1 (WAVH1), and WAV3 HOMOLOG 2 (WA $V H 2$ ), belong to the same group. Surprisingly, although the wav3wavh1wavh2 triple mutant had abnormal root gravitropic response, the single and double mutants were comparatively normal. In the present study, mutation of a single gene in rice, sorl, led to the observed deficiency in root gravitropic response (Figures 1, 2, 3). The molecular mechanisms that control root gravitropism are likely to be considerably different between rice and Arabidopsis; this difference may be caused by the functional redundancy between the Arabidopsis proteins that contain both RING and vWFA domains. In rice, six genes encoding proteins containing both RING and vWFA domains were found (Figure 5). Only one of these proteins, SOR1, belongs to the same group as WAV3, WAVH1, and WAVH2 (Figure 5). Thus, in rice, the control of abnormal gravitropic responses by a single gene (sor1) differs from that in Arabidopsis, in which three related genes control this response.

Other rice mutants with altered root gravitropic responses have been isolated: RM109 (Hao and Ichii 1999) and aem1 (Debi et al. 2003, 2005). In the RM109 mutant, root elongation to slantwise direction differs from that in WT. The seminal roots of aem 1 elongate normally, but respond more slowly to gravity than WT. The root gravitropic response likely depends on the difference in auxin concentration between the upper and lower cells due to amyloplast sedimentation in the columella cells of the root tip. Morita and Kyozuka (2007) demonstrated that the auxin transport-related gene OsPID is associated with the gravitropic response in rice roots. Ge et al. (2004) identified a regulator of auxin distribution, OsRAA, that controls the direction of root growth in rice. The Arabidopsis WAV3 family, which has high sequence similarity with rice SOR1, controls the root growth pattern, in particular the gravitropic response, via mechanisms that involve auxin transport and/or signaling (Stone et al. 2005). Further functional studies are needed to determine the relationship between sor1, root gravitropism, and hormones.

The sor 1 mutant has relatively thick roots (data not shown) that elongate above and just below the soil surface beginning at the seedling stage. In recent years, root research in cereals has focused on designing root system architecture to optimize nutrient acquisition and enable sustainable production (Hodge et al. 2009; King et al. 2003; Lynch and Brown 2012; Lynch 2013; Rich and Watt 2013). Shallow root systems contribute to efficient absorption and accumulation of nutrients from the soil surface; they are able to reach shallow soil horizons, thus enhancing phosphorus acquisition (Ge et al. 2000; Lynch 2011). Untilled fields gradually accumulate fertilizers and nutrients from decomposing crop residue near the soil surface (Boone 1988). In over-fertilized fields, phosphorus significantly accumulates in the topsoil (Phupaibul et al. 2004). In paddy fields in reclaimed tidal flats, more than $10 \%$ of the nutrients supplied by chemical fertilizers are lost due to surface runoff (Cho et al. 2008). Excessive $\mathrm{Fe}^{2+}$ content in the reduced layer is produced by waterlogging (Ponnamperuma et al. 1967; Yoshida 1981). The oxidation-reduction potential decreases in paddy soils, because gaseous oxygen is not supplied under swamp condition (Kohno et al. 1995). When oxygen is used up, Fe is reduced; consequently excess $\mathrm{Fe}^{2+}$ toxicity is produced in paddy soil solution (Kohno et al. 1995). There is less $\mathrm{Fe}^{2+}$ in the upper layers of submerged paddy soils, and soil-surface roots decrease the uptake of iron. Therefore, the mutant sor 1 gene and other genes for soil-surface rooting may be useful for increasing the efficiency of absorption of nutrients accumulated at the soil surface in untilled culture systems and for increasing tolerance to some of the problematic soil types.

Earlier, we identified four QTLs for soil-surface rooting on chromosomes 3, 4, 6, and 7 in three field evaluations (Uga et al. 2012). The major QTL on chromosome 7 was detected in all three field evaluations and by the cup method. The QTL on the terminal region of the short arm chromosome 4 was detected only at the heading stage in 2009. Furthermore, the QTL on chromosome 4 could not be detected by the cup method, so we have been unable to carry out fine-mapping of this QTL. Although further analyses are necessary to determine whether the QTL on chromosome 4 is the same as SOR1, this mutant sor1 gene may be useful for breeding cultivars with enhanced soil-surface rooting.

\section{Conclusion}

The primary roots of the soil-surface rooting mutant lose the root-specific gravitropic response at an early growth stage. The sor 1 (soil-surface rooting 1), a rice mutant causing soil-surface rooting and altered root gravitropic response, is allelic to Os04g0101800 on the terminal region of the short arm of chromosome 4. The 33-bp deletion in Os04g0101800 is responsible for the mutant phenotypes. 


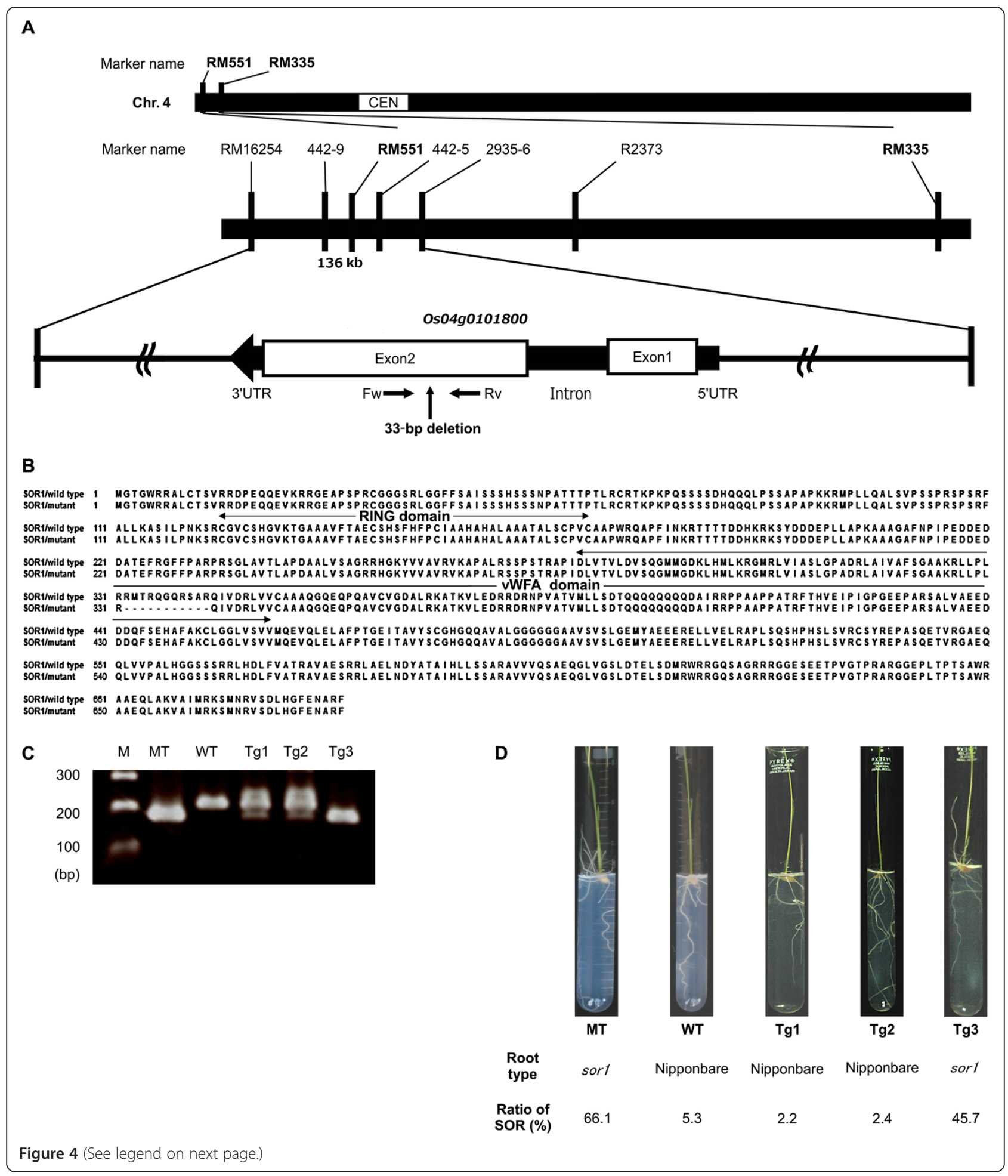


(See figure on previous page.)

Figure 4 Map position and complementation of the candidate gene for soil-surface rooting. (A) Fine mapping of the SOR1 locus, carried out by using SOR-type plants, indicated that the DNA marker RM551 on chromosome 4 co-segregated with soil-surface rooting. The SOR1 locus was identified in a 136-kb region between markers RM16254 and 2935-6. The Os04g0101800 gene is shown as a black arrow, with white boxes indicating the exons. The second exon of the sor 1 mutant allele contains a 33-bp genomic deletion. FW and RV, specific primers used to confirm the deletion. (B) Alignment of SOR1 (wild-type and mutant) amino acid sequences. The positions of the zinc finger (RING finger) domain (aa124-170) and the VWFA (von Willebrand factor type $\mathbf{A}$ ) domain (aa279-460) are indicated above the sequences. The 11-aa deletion (aa332-342) in the vWFA domain of the mutant is shown with dashes (-). (C) Confirmation of the genomic deletion in the mutant by analysis of the PCR amplicon size in wild-type (WT), mutant (MT), and transgenic plants (Tg1-3). Tg1 and Tg2 were transformed with a6677-bp genomic fragment containing Os04g0101800; Tg3 was transformed with an empty vector. M, DNA marker. (D) Phenotyping of soil-surface rooting by the glass tube method (top line) and ratio of soil-surface rooting (SOR) by the basket method (bottom line) in the mutant, wild-type, and transgenic plants.

\section{Methods}

\section{Plant materials}

A mutant with primary roots distributed at the soil surface was detected in an $\mathrm{M}_{2}$ mutant population regenerated from seed calli of the japonica rice (O. sativa L.) cultivar 'Nipponbare' (Hirochika 1997). This population was grown in 2004 in the paddy field of the Institute of Plant Science and Resources, Okayama University (Kurashiki, Okayama, Japan). To confirm soil-surface rooting in the mutant line, $15 \mathrm{M}_{3}$ progeny from a mutant plant were cultivated in the paddy field of the Experimental Farm Station, Graduate School of Life Sciences, Tohoku University (Kashimadai, Osaki, Miyagi, Japan) in 2005. The seeds of mutant plants with confirmed soil-surface rooting $\left(\mathrm{M}_{4}\right)$ were used for further studies.

For genetic analysis, we used $F_{2}$ populations derived from crosses between the mutant and the indica rice cultivar 'Kasalath' or between the mutant and WT 'Nipponbare'. All seeds were soaked in water at $60^{\circ} \mathrm{C}$ for $10 \mathrm{~min}$ and then washed with running tap water for $20 \mathrm{~min}$. Washed seeds were soaked in $0.2 \%(\mathrm{v} / \mathrm{v})$ plant preservative mixture (PPM; Plant Cell Technology, Inc., Washington, DC, USA) in a 6$\mathrm{cm}$ glass Petri dish. Seeds were incubated at $30^{\circ} \mathrm{C}$ for $2 \mathrm{~d}$ to promote uniform germination.

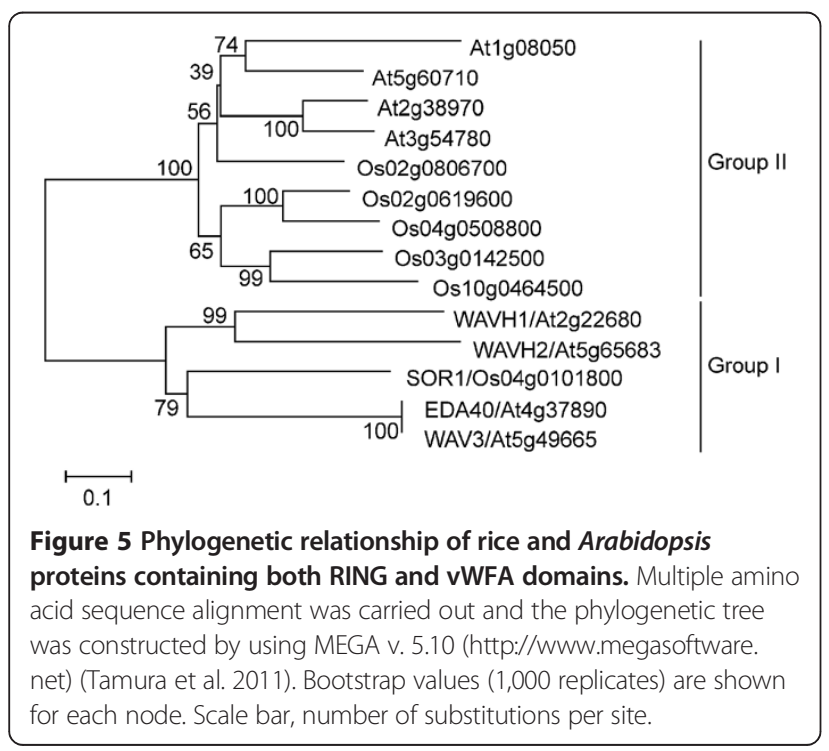

\section{Root vertical growth angle}

We measured the vertical growth angle of primary roots by using the basket method (Oyanagi et al. 1993; Nakamoto and Oyanagi 1994). Soil containing chemical fertilizer (Nursery culture soil No. 3; Mitsui-Toatsu, Tokyo, Japan: N, $0.7 \mathrm{~g} \cdot \mathrm{kg}^{-1}$; P, $1.2 \mathrm{~g} \cdot \mathrm{kg}^{-1}$; K, $0.6 \mathrm{~g} \cdot \mathrm{kg}^{-1}$ ) and soil without fertilizer (Shibanome-tsuchi; Kikuchi Industry Co., Ltd., Tochigi, Japan) were mixed in a 1:1 ratio and placed into plastic pots $(11 \mathrm{~cm}$ diameter $\times 15 \mathrm{~cm}$ height, with a $1-\mathrm{cm}$ diameter hole in the bottom) to a depth of $4 \mathrm{~cm}$. A stainless steel wire basket $(6 \mathrm{~cm}$ diameter $\times 3 \mathrm{~cm}$ depth; Figure $1 \mathrm{G}$ and $\mathrm{H}$ ) was buried just under the soil surface (open side up) in each pot. The pots were placed inside a plastic container $(35 \times 60 \times 20 \mathrm{~cm})$, and one germinated seed was placed at the center of each basket with the embryo facing upward on the soil in each plant pot. The soil in each pot was watered to maintain a sufficient level of moisture, and the seeds were embedded at a depth of $1 \mathrm{~cm}$. The pots were covered with a vinyl sheet to prevent desiccation until the shoot tip emerged. From the second leaf stage on, the water level in each plastic container was maintained at the soil surface level by using tap water. The plants were grown in a greenhouse at $20-30^{\circ} \mathrm{C}$ under natural light.

The baskets were dug out when the plants were at the third, fifth, and seventh leaf stages (Figure $1 G$ and $H$ ). The soil attached to the baskets was removed carefully without cutting the primary roots. Each basket was divided into four angle areas: $<0^{\circ}, 0-30^{\circ}, 30-60^{\circ}$, and $60-$ $90^{\circ}$. The gravitropic and horizontal directions were $90^{\circ}$ and $0^{\circ}$, respectively. We counted the number of primary roots emerging from the basket in each angle area.

\section{Direction of elongation of the primary roots and shoots during seedling development}

The direction of elongation was determined by using a bending method. Germinated seeds were sown just beneath the surface of $1.5 \%$ agar (Wako Pure Chemical Industries, Ltd., Osaka) in plastic trays $(22 \times 14 \times 4 \mathrm{~cm})$ with the embryos facing upward (Figure 3A). The trays were placed in a growth chamber (Biotron, Nippon Medical \& Chemical Instruments Co., Ltd., Osaka) under white light (photosynthetically active radiation equal to $100 \mu \mathrm{mol} /$ $\mathrm{m}^{2} \cdot \mathrm{s}^{-1}$ ) at $25^{\circ} \mathrm{C}$ and $90 \%$ relative humidity. After $18 \mathrm{~h}$, 
the trays were set on their short sides (Figure 3B). After an additional $10 \mathrm{~h}$, the trays were rotated $90^{\circ}$ clockwise (Figure 3C). The direction of seminal root elongation was photographed and measured using Image $J$ software (Wayne Rasband, U.S. National Institutes of Health, Bethesda, MD, USA; http://rsbweb.nih.gov/ij/docs/faqs. html).

\section{Soil-surface rooting at the seedling stage}

For the cup method (Uga et al. 2012), each $F_{2}$ plant was grown in a cylindrical plastic cup $(3.7 \mathrm{~cm}$ diameter and $4 \mathrm{~cm}$ depth; Beaker PP, AS ONE Corporation, Osaka, Japan) (Figure $1 C$ and D). Small holes were made in the bottom of each cup for supplying water. The cups were filled with soil (Rice nursery culture soil No. 3). Forty cups were placed in a stainless steel tray $(32 \times 25 \times$ $5.3 \mathrm{~cm}$ ) with drainage holes. Each germinated seed was sown at the center of a cup in a randomized complete block design, and covered with a 1-cm layer of soil without fertilizer (Shibanome-tsuchi). The tray was placed in a large plastic container $(44.5 \times 32.5 \times 7 \mathrm{~cm})$. Until the second leaf stage, the water level was maintained at $2 \mathrm{~cm}$ above the soil surface from a supply beneath the tray. From the second leaf stage to the time of rooting assessment, the water level was maintained at the level of the soil surface. The plants were grown in a greenhouse at $20-30^{\circ} \mathrm{C}$ under natural day length. At the third leaf stage, the top layer of soil covering the cups was removed carefully without cutting primary roots that had grown over the edges of cups, and the cups were removed from the tray. The primary roots that had elongated past the edge of the cup were counted as soil-surface roots (Figure $1 \mathrm{C}$ and D). The plants were then removed from the cups, and the soil attached to the roots was washed away. The total number of roots was counted for each plant. The soilsurface root ratio for each plant was defined as the number of soil-surface roots divided by the total number of primary roots, and was expressed as a percentage.

For the glass tube method, one germinated seed was sown in a glass tube $(1.8 \times 18 \mathrm{~cm})$ filled with $10 \mathrm{ml}$ of $0.4 \%(\mathrm{w} / \mathrm{v})$ agar, and the opening of the tube was covered with aluminum foil. Plants were cultured in a growth chamber as for the direction of elongation assay for $7 \mathrm{~d}$. Plants with roots that elongated on the upper side of the agar surface were considered as the mutant type (Figure 1E), and those with roots that elongated in the agar as WT (Figure 1F).

After evaluating the gravitropic response of $\mathrm{F}_{2}$ seedlings from a cross between the sor 1 mutant and WT Nipponbare, we transplanted the seedlings into the center of baskets, so that the coleoptilar node base was embedded into soil at a depth of $1 \mathrm{~cm}$. At the seventh leaf stage, we counted the number of primary roots that emerged from the $<0^{\circ}$ angle area (i.e., above the soil surface) and the total number of primary roots, and calculated the soilsurface rooting ratio from these values.

\section{Mapping of the gene responsible for soil-surface rooting}

Seventy DNA markers identified polymorphic between Nipponbare and Kasalath were used for rough mapping (Additional file 1). DNA markers were selected at an average interval of $24.7 \mathrm{cM}$. The primer sequences and PCR conditions were as described (Temnykh et al. 2000; McCouch et al. 2002).

Seven DNA markers located on the short arm of chromosome 4 were used for fine mapping (Additional file 2). The simple sequence repeat (SSR) markers RM16254, RM 551, and RM335 were obtained from Gramene (http:// www.gramene.org/). The cleaved amplified polymorphic sequence marker 22373 was obtained from the Rice Genome Research Program (http://rgp.dna.affrc.go.jp/E/index.html). The remaining three DNA markers were designed to detect insertions or deletions by comparison with the genomic sequence databases for Nipponbare (Rice Annotation Project Database; http://rapdb.dna.affrc.go.jp/) and 93-11 (Rice Information System; http://rice.genomics.org.cn).

DNA was extracted from a leaf tip $(2 \mathrm{~cm})$ of each $\mathrm{F}_{2}$ plant. Each leaf tip was placed in a microcentrifuge tube containing extraction buffer (200 mMTris- $\mathrm{HCl}$ [pH 8.0], $250 \mathrm{mM} \mathrm{NaCl}, 25 \mathrm{mM}$ EDTA, 0.5\% [w/v] sodium dodecyl sulfate), and homogenized by using a TissueLyser (Qiagen, Venlo, Netherlands). DNA was precipitated with isopropanol and resuspended in $50 \mu \mathrm{l}$ of $\mathrm{TE}$ buffer (10 mM Tris- $\mathrm{HCl}$ [pH 8.0], 1 mM EDTA). The PCR profile involved an initial denaturation of $94^{\circ} \mathrm{C}$ for $2 \mathrm{~min}$ followed by 35 cycles of $94^{\circ} \mathrm{C}$ for $30 \mathrm{sec}, 55^{\circ} \mathrm{C}$ for $30 \mathrm{sec}$, $72^{\circ} \mathrm{C}$ for $30 \mathrm{sec}$, and a final extension for $4 \mathrm{~min}$ at $72^{\circ} \mathrm{C}$ by using Taq polymerase (TaKaRa, Otsu, Japan). The amplified fragments and the products of their digestion by restriction enzymes were analyzed by electrophoresis on 1.5 or $3.0 \%$ agarose gels.

\section{Complementation analysis of the candidate sor 1 gene}

We used a 6677-bp genomic DNA fragment of Nipponbare that contained the entire Os04g0101800 coding region, the 2052-bp upstream sequence, and the 1037-bp downstream sequence. The $a t t B$ PCR products were cloned into the pDONR221 vector (Life Technologies, California, USA). The cloned fragment was recombined into pFAST-G01 (Inplanta Innovations, Yokohama, Japan) by using LR Clonase (Invitrogen). The construct was transformed into Agrobacterium tumefaciens strain EHA105. Transgenic lines were generated by transformation of the mutant plants with a Sor1 (wild-type) allele or control empty vector. The seminal root direction of the $T_{1}$ seeds was examined by using the glass tube method. $\mathrm{T}_{1}$ seedlings were transplanted into pots, and soil-surface rooting was analyzed by using the basket method. 
The absence or presence of the 33-bp deletion in Os04 g0101800 was determined by PCR with specific primers FW (5' -AGCACCTTGGTGGCCTTG-3') and RV (5'-C CTCGTCATCGCCTCTCTC-3'). PCR was performed by using PrimeSTAR HS DNA polymerase (TaKaRa, Otsu, Japan) in a volume of $10 \mu$ l that contained $1 \times$ PrimeSTAR buffer, $200 \mu \mathrm{M}$ of each dNTP, $0.3 \mu \mathrm{M}$ of each primer, 0.5 $\mathrm{U}$ PrimeSTAR polymerase, and the template. The PCR program was $1 \mathrm{~min}$ at $94^{\circ} \mathrm{C}$, followed by 30 cycles of $10 \mathrm{~s}$ at $98^{\circ} \mathrm{C}$ and $30 \mathrm{~s}$ at $68^{\circ} \mathrm{C}$, with a final extension step of 5 min at $72^{\circ} \mathrm{C}$. The PCR fragments were analyzed by electrophoresis on $3.0 \%$ agarose gels.

\section{Phylogenetic analysis}

Multiple amino acid sequence alignment was carried out and the phylogenetic tree was constructed by using MEGA v. 5.10 (http://www.megasoftware.net) (Tamura et al. 2011). Bootstrap values (1,000 replicates) are shown for each node, and the scale bar indicates the number of substitutions per site. Sequences of putative genes in rice and Arabidopsis encoding proteins that contain both vWFA and RING domains were obtained by searching the RAP-DB database (http://rapdb.dna.affrc.go.jp/index.html) and TAIR (http:// www.arabidopsis.org/index.jsp), respectively.

\section{Additional files}

Additional file 1: Markers used for rough mapping of the entire genome. Map distance (Map dist.) is shown as genetic distance (cM) from the $3^{\prime}$ end of the short arm of each chromosome (Chr.). SSR, simple sequence repeat marker; STS, sequence-tagged site marker.

Additional file 2: Markers in the terminal region of the short arm of chromosome $\mathbf{4}$ used for fine mapping. SSR, simple sequence repeat marker; CAPS, cleaved amplified polymorphic sequence marker.

\section{Competing interests}

The authors declare that they have no competing interests.

\section{Authors' contributions}

MM, AM and HH provided the mutant seeds. MM, EH, SN and TS generated $F_{2}$ and $F_{3}$ seeds for genotyping and phenotyping. EH performed the experiments of root assays and molecular analysis. EH, SN, KS, MO, YU, AH and TS designed and discussed the research. EH, KS, MO and TS wrote the manuscript. All authors approved the manuscript.

\section{Acknowledgments}

This work was supported by KAKENHI \#23380189 (Grant-in-Aid for Scientific Research [B]) from the Ministry of Education, Culture, Sports, Science, and Technology of Japan. The authors thank Dr. Jun Hidema, Dr. Shusei Sato and Dr. Mika Teranishi (Graduate School of Life Sciences, Tohoku University) for their valuable suggestions.

\section{Author details}

${ }^{1}$ Graduate School of Life Sciences, Tohoku University, 2-1-1 Katahira, Aoba-ku, Sendai, Miyagi 980-8577, Japan. ${ }^{2}$ Present address: Plant Breeding, Genetics and Biotechnology Division, International Rice Research Institute, DAPO Box 7777, Metro Manila, Philippines. ${ }^{3} J a p a n$ International Research Center for Agricultural Sciences, 1-1 Ohwashi, Tsukuba, Ibaraki 305-8686, Japan. ${ }^{4}$ National Institute of Agrobiological Sciences, 2-1-2 Kannondai, Tsukuba, Ibaraki 305-8602, Japan. ${ }^{5}$ Institute of Plant Science and Resources, Okayama University, 2-20-1, Kurashiki, Okayama 710-0046, Japan. ${ }^{6}$ RIKEN Innovation
Center, Ion Beam Breeding Laboratory, 2-1 Hirosawa, Wako, Saitama 351-0198, Japan.

Received: 19 April 2013 Accepted: 15 November 2013 Published: 20 November 2013

\section{References}

Boone FR (1988) Weather and other environmental factors influencing crop responses to tillage and traffic. Soil Tillage Res 11:283-324

Chaitra J, Vinod MS, Sharma N, Hittalmani S, Shashidhar HE (2006) Validation of markers linked to maximum root length in rice (Oryza sativa L.). Curr Sci 90:835-838

Chhun T, Taketa S, Tsurumi S, Ichii M (2003) Interaction between two auxin-resistant mutants and their effects on lateral root formation in rice (Oryza sativa L.). J Exp Bot 54:2701-2708

Cho JY, Son JG, Choi JK, Song CH, Chung BY (2008) Surface and subsurface losses of $\mathrm{N}$ and $\mathrm{P}$ from salt-affected rice paddy fields of Saemangeum reclaimed land in South Korea. Paddy Water Environ 6:211-219

Debi BR, Mushika J, Taketa S, Miyao A, Hirochika H, Ichii M (2003) Isolation and characterization of a short lateral root mutant in rice (Oryza sativa L.) Plant Sci 165:895-903

Debi BR, Chhun T, Taketa S, Tsurumi S, Xia K, Miyao A, Hirochika H, Ichii M (2005) Defects in root development and gravity response in the aem1 mutant of rice are associated with reduced auxin efflux. J Plant Physiol 162:678-685

Ge Z, Rubio G, Lynch JP (2000) The importance of root gravitropism for inter-root competition and phosphorus acquisition efficiency: results from a geometric simulation model. Plant Soil 218:159-171

Ge L, Chen H, Jian J-F, Zhao Y, Xu M-L, Xu Y-Y, Tan K-H, Xu Z-H, Chong K (2004) Overexpression of OsRAA1 causes pleiotropic phenotypes in transgenic rice plants, including altered leaf, flower, and root development and root response to gravity. Plant Physiol 135:1502-1513

Hao Z, Ichii M (1999) A mutant RM109 of rice (Oryza sativa L.) exhibiting altered lateral root initiation and gravitropism. Jpn J Crop Sci 68:245-252

Hardtke CS, Okamoto H, Stoop-Myer C, Deng XW (2002) Biochemical evidence for ubiquitin ligase activity of the Arabidopsis COP1 interacting protein 8 (CIP8). Plant J 30:385-394

Hirochika H (1997) Retrotransposons of rice: their regulation and use for genome analysis. Plant Mol Biol 35:231-240

Hodge A, Berta G, Doussan C, Merchan F, Crespi M (2009) Plant root growth, architecture and function. Plant Soil 321:153-187

Holm M, Ma LG, Qu LJ, Deng WX (2002) Two interacting bZIP proteins are direct targets of COP1-mediated control of light-dependent gene expression in Arabidopsis. Genes Dev 16:1247-1259

$\mathrm{Hu}$ J, Aguirre M, Peto C, Alonso J, Ecker J, Chory J (2002) A role for peroxisomes in photomorphogenesis and development of Arabidopsis. Science 297:405-409

Ichii M, Ishikawa M (1997) Genetic analysis of newly induced short-root mutants in rice (Oryza sativa L.). Breed Sci 47:121-125

Inukai Y, Miwa M, Nagato Y, Kitano H, Yamauchi A (2001) Characterization of rice mutants deficient in the formation of crown roots. Breed Sci 51:123-129

Iwao MJ, You T, Taketa S, Miyao A, Hirochika H, Ichii M (2005) Molecular genetic analysis of a Tos 17-tagged mutant line related to root morphology in rice. Breed Res 7:171-178

Kim CM, Park SH, Je Bl, Park SH, Park SJ, Piao HL, Eun MY, Dolan L, Han CD (2007) OsCSLD1, a cellulose synthase-like D1 gene, is required for root hair morphogenesis in rice. Plant Physiol 143:1220-1230

King J, Gay A, Sylvester-Bradley R, Bingham I, Foulkes J, Gregory P, Robinson D (2003) Modelling cereal root systems for water and nitrogen capture: Towards an economic optimum. Ann Bot 91:383-390

Kohno E, Ogawa Y, Iwata S (1995) Productivity of paddy fields. In: Tabuchi T, Hasegawa S (eds) Paddy fields in the world. The Japanese Society of Irrigation, Drainage and Reclamation Engineering. Tokyo, pp 341-349

Lafitte HR, Champoux MC, McLaren G, OToole JC (2001) Rice root morphological traits are related to isozyme group and adaptation. Field Crops Res 71:57-70

Liao H, Yan X, Rubio G, Beebe SE, Blair MW, Lynch JP (2004) Genetic mapping of basal root gravitropism and phosphorus acquisition efficiency in common bean. Funct Plant Biol 31:959-970

Lynch JP (2011) Root phenes for enhanced soil exploration and phosphorus acquisition: tools for future crops. Plant Physiol 156:1041-1049

Lynch JP (2013) Steep, cheap and deep: an ideotype to optimize water and N acquisition by maize root systems. Ann Bot 112:347-357 
Lynch JP, Brown KM (2001) Topsoil foraging - an architectural adaptation of plants to low phosphorus availability. Plant Soil 237:225-237

Lynch JP, Brown KM (2012) New roots for agriculture: exploiting the root phenome. Phil Trans Royal Soc B Biolog Sci 367:1598-1604

Mano Y, Muraki M, Fujimori M, Takamizo T, Kindiger B (2005) Identification of QTL controlling adventitious root formation during flooding conditions in teosinte (Zea mays ssp. huehuetenangensis) seedlings. Euphytica 142:33-42

Manske GGB, Ortiz-Monasterio Jl, Ginkel MV, Gonzalez RM, Rajaram S, Molina E, Vlek PLG (2000) Traits associated with improved P-uptake efficiency in CIMMYT's semi dwarf spring bread wheat grown on an acid Andisol in Mexico. Plant Soil 221:189-204

Matsuda N, Suzuki T, Tanaka K, Nakano A (2001) Rma 1, a novel type of RING finger protein conserved from Arabidopsis to human, is a membrane-bound ubiquitin ligase. J Cell Sci 114:1949-1957

McCouch SR, Teytelman L, Xu Y, Lobos KB, Clare K, Walton M, Fu B, Maghirang R, Li Z, Xing Y, Zhang Q, Kono I, Yano M, Fjellstrom R, DeClerck G, Schneider D, Cartinhour S, Ware D, Stein L (2002) Development and mapping of 2240 new SSR markers for rice (Oryza sativa L.). DNA Res 9:199-207

Molnảr G, Bancoș S, Nagy F, Szekeres M (2002) Characterisation of BRH1, a brassinosteroid-responsive RING-H2 gene from Arabidopsis thaliana. Planta 215:127-133

Morita Y, Kyozuka J (2007) Characterization of OSPID, the rice ortholog of PINOID, and its possible involvement in the control of polar auxin transport. Plant Cell Physiol 48:540-549

Morita S, Yamazaki K (1993) Root system. In: Matsuo T, Hoshikawa K (eds) Science of the Rice Plant, vol 1, Morphology. Food and Agriculture Policy Research Center, Tokyo, pp 161-186

Nakamoto T, Oyanagi A (1994) The direction of growth of seminal roots of Triticum aestivum L. and experimental modification thereof. Ann Bot 73:363-367

Oyanagi A, Nakamoto T, Morita S (1993) The gravitropic response of roots and the shaping of the root system in cereal plants. Environ Exp Bot 33:141-158

Phupaibul P, Chitbuntanorm C, Chinoim N, Kangyawangha P, Matoh T (2004) Phosphorus accumulation in soils and nitrate contamination in underground water under export-oriented asparagus farming in Nong Ngu Lauen village, Nakhon Pathom province, Thailand. Soil Sci Plant Nutr 50:385-393

Ponnamperuma FN, Tianco EM, Loy T (1967) Redox equilibria in flooded soils: I. the iron hydroxide systems. Soil Sci 103:374-382

Rich SM, Watt M (2013) Soil conditions and cereal root system architecture: review and considerations for linking Darwin and Weaver. J Exp Bot 64:1 193-1208

Sakai T, Michizuki S, Haga K, Uehara Y, Suzuki A, Harada A, Wada T, Ishiguro S, Okada K (2012) The wavy growth 3 E3 ligase family controls the gravitropic response in Arabidopsis roots. Plant J 70:303-314

Serrano M, Guzmán P (2004) Isolation and gene expression analysis of Arabidopsis thaliana mutants with constitutive expression of ATL2, an early elicitor-response RING-H2 zinc-finger gene. Genetics 167:919-929

Stone SL, Hauksdóttir H, Troy A, Herschleb J, Kraft E, Callis J (2005) Functional analysis of the RING-type ubiquitin ligase family of Arabidopsis. Plant Physiol 137:13-30

Suzuki N, Taketa S, Ichii M (2003) Morphological and physiological characteristics of a root-hairless mutant in rice (Oryza sativa L.). Plant Soil 255:9-17

Tamura K, Peterson D, Peterson N, Stecher G, Nei M, Kumar S (2011) MEGA5: Molecular evolutionary genetics analysis using maximum likelihood, evolutionary distance, and maximum parsimony methods. Mol Biol Evol 28:2731-2739

Temnykh S, Park WD, Ayres N, Cartinhour S, Hauck N, Lipovich L, Cho YG, Ishii T, McCouch SR (2000) Mapping and genome organization of microsatellite sequences in rice (Oryza sativa L.). Theor Appl Genet 100:697-712

Ueno K, Sato T (1989) Aerial root formation in rice ecotype Bulu. Jpn J Trop Agr 33:173-175

Ueno K, Sato T (1992) Varietal difference in growth directions of rice crown roots and relation to gravitropic response and diameter of crown roots. Jpn J Breed 42:779-786

Uga Y, Hanzawa E, Nagai S, Sasaki K, Yano M, Sato T (2012) Identification of qSOR1, a major rice QTL involved in soil surface rooting in paddy fields. Theor Appl Genet 124:75-86

Whittaker CA, Hynes RO (2002) Distribution and evolution of von Willebrand/ Integrin A domains: Widely dispersed domains with roles in cell adhesion and elsewhere. Mol Biol Cell 13:3369-3387

Xie Q, Guo HS, Dallman G, Fang SY, Weissman AM, Chua NH (2002) SINAT5 promotes ubiquitin-related degradation of NAC1 to attenuate auxin signals. Nature 419:167-170
Xu R, Li QQ (2003) A RING-H2 zinc-finger protein gene RIE1 is essential for seed development in Arabidopsis. Plant Mol Biol 53:37-50

Yoshida S (1981) Fundamentals of rice crop science. The International Rice Research Institute. Manila, Philippines

Yuo T, Toyota M, Ichii M, Taketa S (2009) Molecular cloning of a root hairless gene rth1 in rice. Breed Sci 59:13-20

Yuo T, Shiotani K, Shitsukawa N, Miyao A, Hirochika H, Ichii M, Taketa S (2011) Root hairless 2 (rth2) mutant represents a loss-of-function allele of the cellulose synthase-like gene OsCSLD1 in rice (Oryza sativa L.). Breed Sci 61:225-233

doi:10.1186/1939-8433-6-30

Cite this article as: Hanzawa et al:: Isolation of a novel mutant gene for soil-surface rooting in rice (Oryza sativa L.). Rice 2013 6:30.

\section{Submit your manuscript to a SpringerOpen ${ }^{\odot}$ journal and benefit from:}

- Convenient online submission

- Rigorous peer review

- Immediate publication on acceptance

- Open access: articles freely available online

High visibility within the field

- Retaining the copyright to your article

Submit your next manuscript at $\gg$ springeropen.com 